\title{
Study on the Ancestral Temple of Minxi Hakka Areas in China and Its Influence on the Village Form - Example for Zhixi Village
}

\author{
Yongqian Qiu, Ping-Sheng Wu, and Min-Fu Hsu
}

\begin{abstract}
The paper has taken the Zhixi Village for example, the most typical one of Minxi Hakka villages, analyzing the changes of such villages from the beginning of development of the patriarchal clan, then further discussing the impact of Ancestral Temple layout on the village texture form and finally making a conclusion of the types and characteristics of the Ancestral Temple buildings.
\end{abstract}

Index Terms-The ancestral temple, village form, Minxi Hakka areas, Zhixi village.

\section{INTRODUCTION}

The Ancestral Temple is the place for the clansman to worship their ancestors or sages and also an important building type under the patriarchal system in the Chinese rural society. In the traditional society of Han people, such temple is a symbol of power and authority of the patriarchal clan as well as the entrustment for the clansman to glorify and illuminate their own ancestors. The whole clan would put all of their energy, labor force and wealth included so as to construct the temple grandly and magnificently. Making a general survey of remaining Ancestral Temple architecture types of various places dating from previous dynasties, most of which can reflect the comparatively high standard both in artistic style and technical skills, and therefore became the important carrier to make a study on Chinese traditional architecture.

Minxi, historically speaking, Tingzhou, located in the west of Fujian province (the border of Fujian, Guangdong and Jiangxi provinces, is one of the main native places and settlements of Hakka. On account of the respect of ancestors and the common patterns of Surname kinship inhabited together, Minxi Hakka embraces much advanced blood culture as well as the structured and strict family system, moreover, the corresponding family economy benefited from the relative stability of the mountain rice civilization and the farming form of blood groups, they had combined the central plain's architectural art of Han people with the local actual conditions, leading to the formation of large numbers of Tulou settlement buildings with unique style and far-reaching influence as well as the abnormally flourishing architectural art of Ancestral Temples [1]. According to the statistics of related materials, there are thousands of remaining Ancestral Temples of Ming and Qing dynasty in

Manuscript received May 9, 2014; revised July 13, 2014

Yongqian Qiu is with the Department of Architecture, National Cheng Kung University, Taiwan (e-mail: yuengqiang@gmail.com).
Minxi Hakka villages, more than 70 of which have topped Mainland cultural relics protection sites at all levels.

Zhixi Village, located in the south of Liancheng County of Minxi, is the typical example of Minxi Hakka villages and also an old and rare village kept relatively intact in terms of the overall view and building monomer within the Fujian province, therefore, it had been awarded as the Chinese history and culture village in 2011. The Ancestral Temples occupy the largest proportion in the traditional customs of Hakka architecture in this village. The village boasts numerous of such temples, around 40 of which exist comparatively well. It is rare to see such large quantities of temples in contrast to other areas [2]. This paper takes the Zhixi Village for instance to make a research about the Ancestral Temples of Minxi Hakka areas and the influence of such temples towards the village formation. I intend to analyze the evolution process of human settlements from the perspective of clan relations, probe into the effect of the Ancestral Temple's layout on the village texture form and sum up the architectural characteristics of such temples.

\section{ThE DEVElopMENT OF THE Clan AND THE EVOLUTION PROCESS OF THE TRADITIONAL VILLAGES}

\section{A. The Overview of the Patriarchal Clan System of Zhixi Village}

Minxi Hakka people embraces much advanced blood culture, with many small families of genetic connection living together, that is, the production and living is in households unit, which is made up of the couple and their sons and daughters so as to shape a structured and strict family system, furthermore, they advocate the "extended family and nuclear family" system with a few generations under one roof and attach great importance to maintain the cohesion of insiders, you can see how strong is their patriarchal clan concept [3].

Zhixi Village is a traditional settlement composed of Hakka people with four surnames Huang, Yang, Qiu, Hua, and has a population of about 12,000 at present, most of which are Huang and Yang surnamed clansmen, about 1,000 Qiu surnamed people and few Hua surnamed people. Before the Northern Dynasty, Qiu and Hua surnamed Hakka people had been settled down in Zhixi Village, during the period of the late Song and early Yuan Dynasty and the Chenghua period of Ming Dynasty, Yang and Huang surnamed Hakka people arrived here to build the base. Until the late Qing Dynasty, the settlement structure concentrated on Huang and Yang surnamed people had took shape in Zhixi Village, and 
the Huang, Yang, Qiu surnamed people had built hundreds of Ancestral Temples in total, all patriarchal clans compiled genealogical tree and reserved properties, resulting in a quite complete clan system.

\section{B. The Development of Patriarchal Clan and Evolution Progress of Human Settlements of Zhixi Village}

\section{1) The choice of settlement location}

The Hakka place high priority on Fengshui(geomantic theory, Fengshui is an ancient Chinese practice of arranging items so that they are in balance and harmony with their environment). The choice of settlement location should have on-the-spot investigation in accordance with the geographical situation, and should be in balance and harmony with the natural landscape. The location of Zhixi Village is a typical case in point of traditional geomantic pattern. The settlements of Huang and Yang surnamed people are both near the mountain and by the river, Sitting east headed west, with Taoyuan mountain backwards and Zhishui River in front, while the settlements of Qiu surnamed people had fronting water and hills on the back according to the geographical terrain, forming a layout of sitting west to east. The whole village was surrounded by mountains, with Zhishui River flows in the middle, shaping the best living environment in traditional agricultural society - a geomantic layout surrounded by mountains and girdled by a river, with the yin at its back and the yang in front (see Fig. 1).

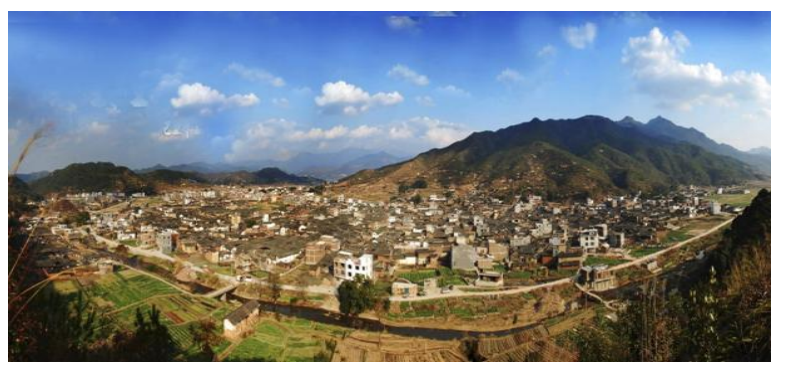

Fig. 1. Full view of Zhixi village.

\section{2) The development of patriarchal clan and evolution progress of human settlements}

Qiu surnamed people was the earliest clan to settle down in Zhixi Village, whose ancestors chose the west of Zhishui River as the location to live because of its higher terrain near the mountain, afterwards the Yang and Huang surnamed people laid their bases of Ancestral Temples respectively in Beiyuan garden and Chashankou, both of which were in higher terrain. With the increase of population, the Qiu, Huang, Yang surnamed people developed towards the flatter terrain facing Zhishui River, with the Ancestral Temples in its center (see Fig. 2).

Due to the Zhishui River as the natural partition, Qiu surnamed people took northeast as the main development direction and therefore formed an independent single-surname structure. However, the settlements of Huang and Yang surnamed people took northwest as the main development direction, and owing to the rapid increase of population, the distribution was intersected, but the characteristic of branch Ancestral Temples concentrated on each surname and each household as well as the relatively concentrated layout could also be recognized from the view of local structure. For example, the surrounding areas centered on Yanghui and Junting Ancestral Temples are basically the Yang surnamed people's settlements, while the surrounding areas centered on Wenchen and Wenqing as well as the Chengchuan Ancestral Temples are undoubtedly the Huang surnamed people's settlements, which show intense Biological characteristics.

In general, the whole Zhixi Village stretches east to west, forming a layout that the ancestral bases embraces outwardly natural growth from the perspective of plane modality, which seems to be out-of-order but actually implies the logic of organic and unconstrained dendrites' growth.

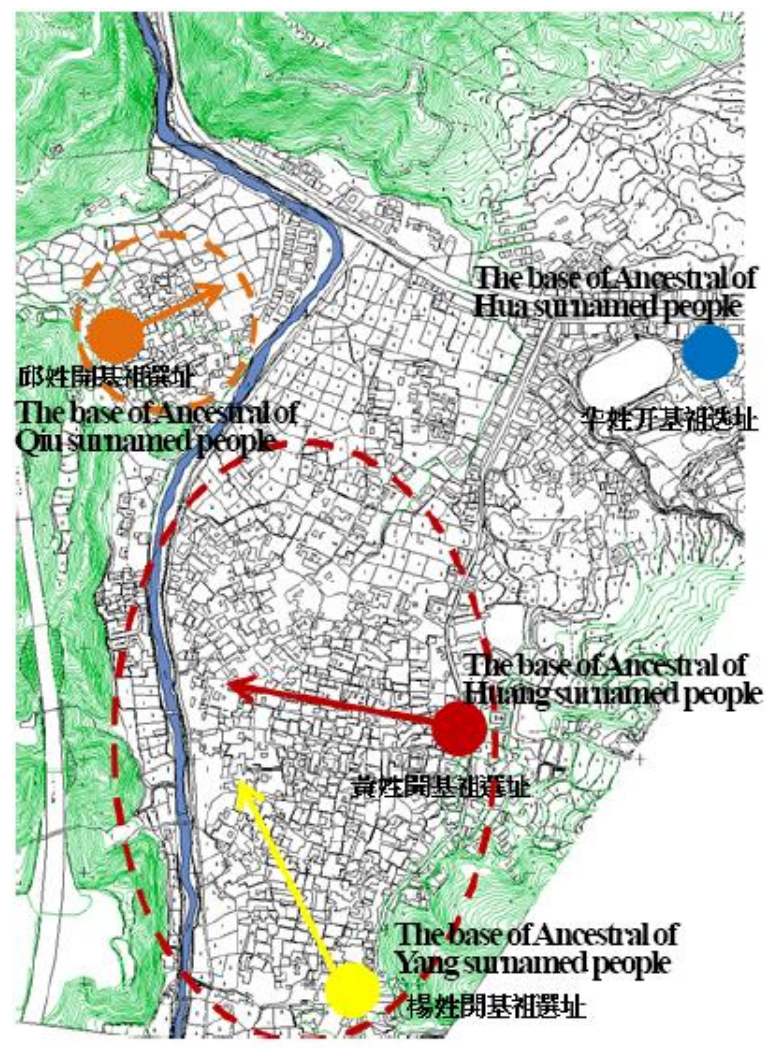

Fig. 2. The evolution of the settlements in Zhixi village.

\section{ThE TRADITIONAL VILLAGE LAYOUT INFLUENCED BY THE ANCESTRAL TEMPLES}

\section{A. The Choice of Location of Ancestral Temples and Distribution}

The Hakka believe that the Ancestral Temple stands for the ancestor and is also the most important place to worshiptheir own ancestors. So it is necessary to devote particular care to the architecture geomancy of such temples so as to more properly settle the ancestral spirits and the generations can also get more blessings from their ancestors. [4] In the heart of Zhixi Hakka, the temples are also the symbol of family and generally located in the most centered or most important site of the settlement of different surnamed people. For instance, the temple base of Huang family is excellent, with the moon pool in front and mountains backwards, which conform to the traditional geomantic pattern that fronting water and with hills on the back, with the yin at its back and the yang in front. 
Zhixi Village is a living place of many surnamed people, all of them had built the central Ancestral Temples to offer sacrifice to their kin ancestors after the base-built in Zhixi. Along with the increase of family population, all branches of the clansman, with Ancestral Temples - centered, multiplied outwardly and established individual branch temple. In terms of level, the central temple is higher than the branch Ancestral Temple, whose daily activities and management are all independent except taking part in the-whole-clan activities such as ancestor worship and family genealogy compiling. Hence, with the development and progress of the patriarchal clan, Zhixi Village gradually shaped the spatial classification of ancestor worship of Ancestral Templesbranch temples - central temples, then the distribution is stretched from the higher-terrain temples towards wider areas facing the Zhishui River, constituting a pattern of arborization. The Qiu surnamed people's temples are relatively centralized while the Huang and Yang surnamed people's temples are staggered.

\section{B. The Village Texture form Affected by the Ancestral Temples}

As the important material entity of patriarchal system, the Ancestral Temple profoundly influences the growth of whole village texture form. Zhixi Village developed centering on the Ancestral Temples, the branch household on account of the split of patriarchal clan divides spatial domain according to the blood relatives within the territory of the temples and shaped their own independent living groups centered on the branch temples. Each family of each group formed their own smaller groups, which was also surrounded by the proximate grade Ritual center - made up of branch temples or family's Ancestral Temples. Consequently the village is formed as the multilevel spatial structure with Ancestral Shrine as the focus, and several branch temples and family Ancestral Temples as its sub center. Each temple has a mini-square for the gathering of clan members, the layout of buildings around and street organizations are both relatively neat, becoming the significant space joint of the village.

In the village, owing to the high space level, the Ancestral Temple is regarded as the hub of patriarchal clan lifeblood and has a sacred and inviolable status. Therefore, the newly-built architecture layout affected by the concept of clan system will abide by the Axis direction of the temples. Through observation we can find that the temples located in Zhixi Village will to some extent influence the combination form of the surroundings: the single axis of the surrounding buildings basically coincide with the orientation of the Ancestral Temples while the cluster combined by the temples with the buildings structurally spread out here and there in the village (see Fig. 3). However, from the perspective of the whole village, the texture form of which are not constructed completely the same with the orientation of the temples, in the edge of the village and surroundings along the Zhishui River, the form tends to be more liberal and organic(see Fig. 4). The reason of such layout may be the relatively late construction ages; moreover, the buildings had a comparatively far distance away from the temples, the influence of such temples towards the buildings is much weaker.
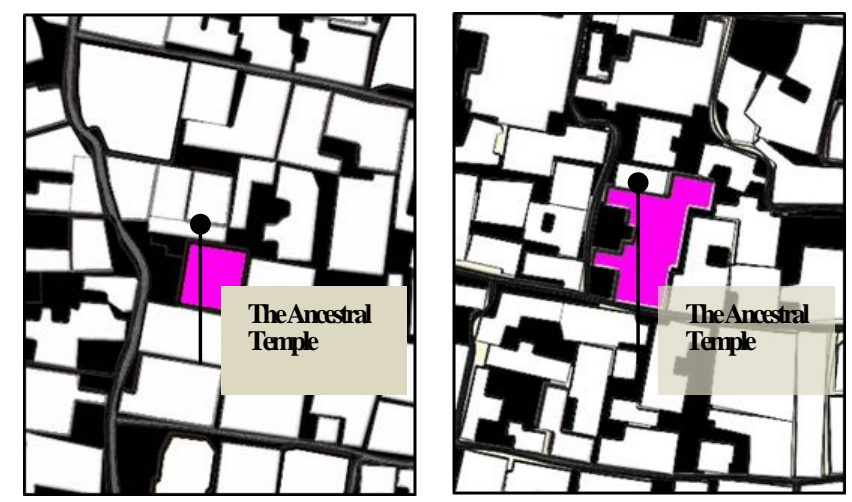

Fig. 3. The distribution of surrounding buildings of ancestral temples.
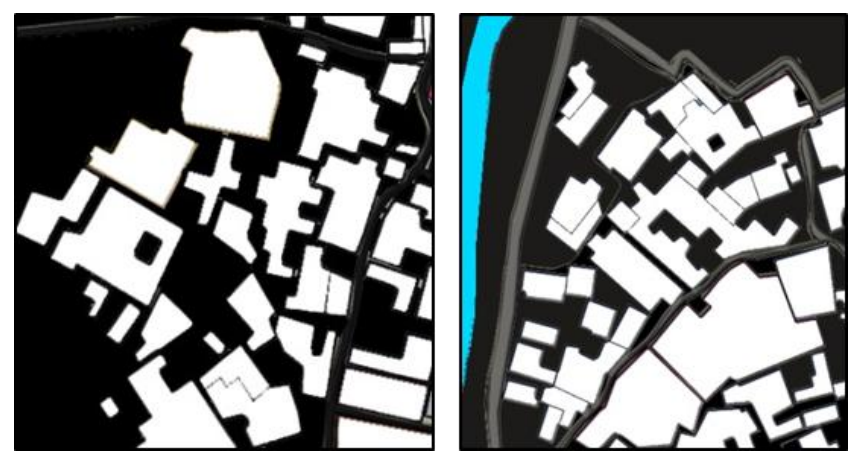

Fig. 4. The distribution of surrounding buildings of non-ancestral temples.

\section{The ARChitectural FeAture of the ANCESTRAL TEMPLE IN ZHIXI VILLAGE}

\section{A. The Types of the Ancestral Temples}

The Ancestral Temples in Zhixi Village have two basic types, one is pure temples built specially for the ancestor worship but not used for living, with standing management body of each clan and organization, supervised by specially-assigned person, and the other one is "temple and place of residence in unity", that is, the axle wire hall is the space of the temple while the horizontal house is the residence. The vast majority of the existing Ancestral Temples in Zhixi Village are all the latter type, which means that the whole dwelling changed into rooms of the temple or the original axle wire hall partly upgraded as the Ancestral Temples, while the horizontal house remains its function of living. The planar system of the above-mentioned two types of temples resembles the spatial arrangement, in spite of the numerous Ancestral Temples, their plane layout and spatial pattern are both programmed, what makes the difference is the discrepancy of scale, width and size [5].

\section{B. Architectural Feature}

The elemental architectural form of the Ancestral Temples in Zhixi Village is "two depth, three bay width", structured by upper and lower halls, between which boasts patio. Each hall covers a large area, with wing-rooms besides it. In the architecture of "temple and place of residence in unity", the temple is always built in the core location of the house so as to worship the ancestors for the convenience of the clan people. The vast majority of such architecture boasts grand scale, taking the Huang surnamed people's Yuxi Ancestral Temple for example it covers a large area and embraces 101 large or small rooms. 
Most of the Ancestral Temples in Zhixi Village are particular about the form of gates, which is the appearance of a building, reflecting the status of the owner of the house. The roof of all the Ancestral Temples' gate has cornice and rake angle, and the upturned roof-ridge is decorated with trespe and grey models, which seems to be rather dexterous. Most of the cornices are decorated with grey models and colour paintings, which are simple and elegant as well as unsophisticated, teemed with artistic expression (see Fig. 5).

The decoration of the Ancestral Temples in Zhixi Village is also diverse. Besides the entrance gate, the hall (especially the upper hall) shall add the ceiling, some even uses caisson on the ceiling, draws color painting in the purline or beam or bracket set with some mascots such as flowers and plants, birds and animals, showing the magnificence, as well as the solemn, elegant and respectful implication.

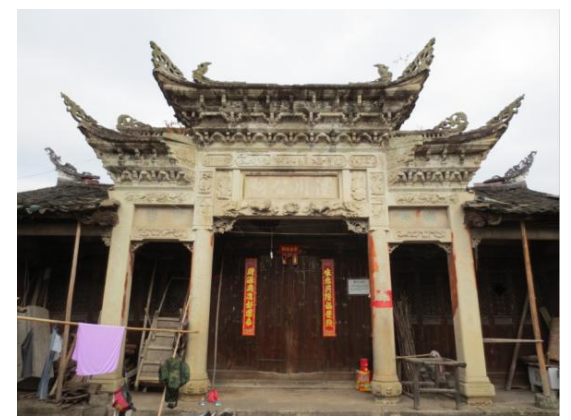

Fig. 5. The gate of ancestral temples.

\section{CONCLUSION}

From the above-mentioned discuss, we can see that the choice of base--built of the ancestors in Zhixi is deeply affected by the geomancy concept, and pay much attention to be in harmony with the natural environment. With the development of the agnation, the human settlements are stretched from the relatively higher terrain towards the direction of the river, shaping the mixed layout of the independent Qiu surnamed people and Huang, Yang surnamed people. The patriarchal clan system of "extended family and nuclear family" had formed the ancestor worship spatial classification of Ancestral Temple - branch Ancestral Temple - centered Ancestral Temple, and also affected the construction axis of the surrounding buildings of the temples, then further influences the whole texture form of the village.
The elemental architectural form of the Ancestral Temples in Zhixi is "two depth, three bay width", the internal architecture lays emphasis on the decoration and boasts grand and magnificent gates, which is a concentrated reflection of Clan culture and regional culture of Zhixi Hakka.

\section{REFERENCES}

[1] J. Lin and H. Lin, Hakka Tulou and Hakka Culture, Taipei: Boyuan Publishing Co. Ltd., 1992, p. 305.

[2] Z. Dai, Fujian Dwellings, Beijing: China Architecture \& Building Press, 2009, p. 113.

[3] Y. Zhang, "Forms and functions of hakka kindreds in west Fujian," Journal of Longyan Teachers College, vol. 23, pp. 90-94, February 2005.

[4] X. Lin and S. Qi, "Discussion on the causes of popular Fengshui in Hakka rural areas and the view of Fengshui on Hakka ancestral temple," Agricultural Archaeology, vol. 6, pp. 221-224, December 2007.

[5] M. Wang, Study on Settlement Patterns of the Zhixi Village, Master's Thesis of Huaqiao University Architecture Department, 2008, p. 68.

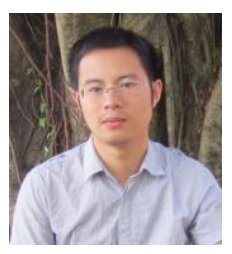

Yongqian Qiu was born in Fujian, China on March 12,1979 . He received his master of engineering at School of Architecture and Urban Planning in Huazhong University of Science and Technology in 2007. And he is currently a doctoral student of Department of Architecture in National Cheng Kung University, Taiwan. And he is also a lecturer of College of Architecture and Urban Planning in Fujian University of Technology. His research interests are architectural histories and cultural heritage conservation.

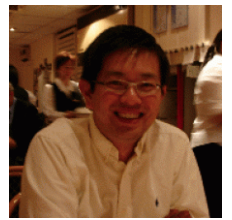

Ping-Sheng Wu is currently working as an associate professor of Department of Architecture in National Cheng Kung University. He received his PHD at Department of Architecture of National Cheng Kung University. His research interests are architectural histories and cultural heritage conservation.

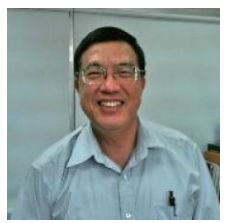

Min-Fu Hsu is a distinguished professor at Department of Architecture of National Cheng Kung University. His research interests are architectural histories and cultural heritage conservation. 